1822. Chen. Interview

https://doi.org/10.30953/tmt.v2.35

\title{
TMT Interview: Milton Chen, CEO, VSee
}

Editor's note: On March $16^{\text {th }}$ and $17^{\text {th }}$, 2017, Telehealth and Medicine Today convened a national conference of opinion leaders to discuss and debate "Technologies and Tactics Transforming Long-term Care." What follows is an interview with Milton Chen, who is who is CEO of VSee, a digital health solution leveraging machine for learning and remote patient monitoring to enable identification of patient deterioration at an early stage.

\section{Introduction [00:00]}

Dr. Milton Chen is a co-founder and CEO of VSee, which is the only approved video telehealth platform used by NASA astronauts aboard the International Space Station. VSee offers clients telehealth platform and digital devices that connect patients with remotely located medical professionals.

During the recent $T M T$-sponsored conference titled, Profitable Scalable and Sustainable Tactics Transforming Long-term Care Telehealth and Medicine, Dr. Chen was asked several questions about his thoughts on telehealth today.

\section{TMT: What are the key factors that influence physician receptiveness, use, and acceptance of telehealth programs? [00:36]}

Dr. Chen: There are two classes of providers. There are providers who are willing to work for Teledoc to make some extra money. And if you work American Well, that's \$28 per call, and you don't get that many calls. So, most physician, at that price, can't get out of bed for that much money. They will find it deeply insulting for someone to pay that little money.

Next, you have physicians who are actually very good. So, for them there's actually no financial incentive to do telemedicine. Do they get more pay? Often, not. Do they see a lot more patients? At most, maybe 10\%, 20\% increase. It's not a ten $X$ increase. You actually don't have strong financial incentive for them to do this. 
1822. Chen. Interview https://doi.org/10.30953/tmt.v2.35

On top of that, most of the telemedicine technology is way too complicated, with a one size fits all. I'll give you an example. Telemedicine today is like EMR (electromagnetic resonance) at MD Anderson. MD Anderson laid off 900 people. Do you know the reason they say they had to off 900 people? When the introduced Epic, decreasing physician, nurse productivity cost them a huge $\$ 100$ million hole. Again, this is a classic example. You introduce a product. It looks great except it causes productivity to decrease. Of course, you have to pay for it.

Telemedicine for the provider is very similar in their eyes. I'm not making a boatload of money, and on top of that my provider efficiency is going to go down. And guess what, adoption is not going to be that good.

In fact, this is one of the root problems in telemedicine adoption over the last 20 or 30 years. Unless you have the provider engagement, there is no incentive.

\section{TMT: What are the untapped telehealth staffing resources in an institution?} [02:26]

Dr. Chen: One of the areas that I find intriguing is that a lot of people are looking for physicians, but there is actually in terms of hospitalists, most of them work here one week, one week off. They are a physician labor pool you can tap into in terms of staffing.

\section{TMT: What insights can you share to make telehealth profitable? [02:46]}

Dr. Chen: There are a bunch of different ways to make money. There are companies out there that are talking down to the seniors. And we think those systems will ultimately fail because when you work with a senior, when they wake up, are not looking for someone to not respect them. They are not looking for someone to talk down to them.

They actually want a face-to-face experience. You just need to able to have a virtual assistant or someway to whether Virtua system was sound way to account for that. 
1822. Chen. Interview

https://doi.org/10.30953/tmt.v2.35

\section{TMT: What are your thoughts about apps for telehealth? [03:22]}

Dr. Chen: We often give the advice that you should not be purely app because you will probably fail. There's over 250 thousand healthcare apps. Most of them will not succeed. So, the app s just a means. Actually, in the healthcare system it's the physicians that will help drive this.

\section{TMT: What are the first steps for VSee in working with clients? [03:40]}

When we work with our partner the first thing we do is, "I go I don't care who you are, we're going to give you a 30-minute design course. You have to become a designer. Because if you're not a designer-you don't need to do full design-you don't have a basis for how to think about hardware and software and workflow. But once you have that design basic training, now you actually can think through these much ; and that will help adoption.

\section{TMT: What's the future for telehealth in the long-term care? [04:11]}

Dr. Chen: Here's one of the reasons I'm really excited about this long-term care space (Fig. 1). If you look at it this graph. this someone's age, right? This is the cost of healthcare. It looks like this classic curve. When you're born it's a little bit expensive. Then you drop down to near zero for a couple of decades, and then it shoots off from there.

If you look at the TeleDoc ${ }^{\circledR}$ or AmericaWell ${ }^{\circledR}$, they are doing great job down here. This is about low acuity. You do a great job here, but you're not moving the needle at all. This is where you have a big impact on healthcare.

In fact, this is why it's great for Tori Cenaj to have put on this conference. I think this is actually the work of this community. This is how you can actually move the needle and actually make an impact. 
1822. Chen. Interview https://doi.org/10.30953/tmt.v2.35

Page 4 of 5

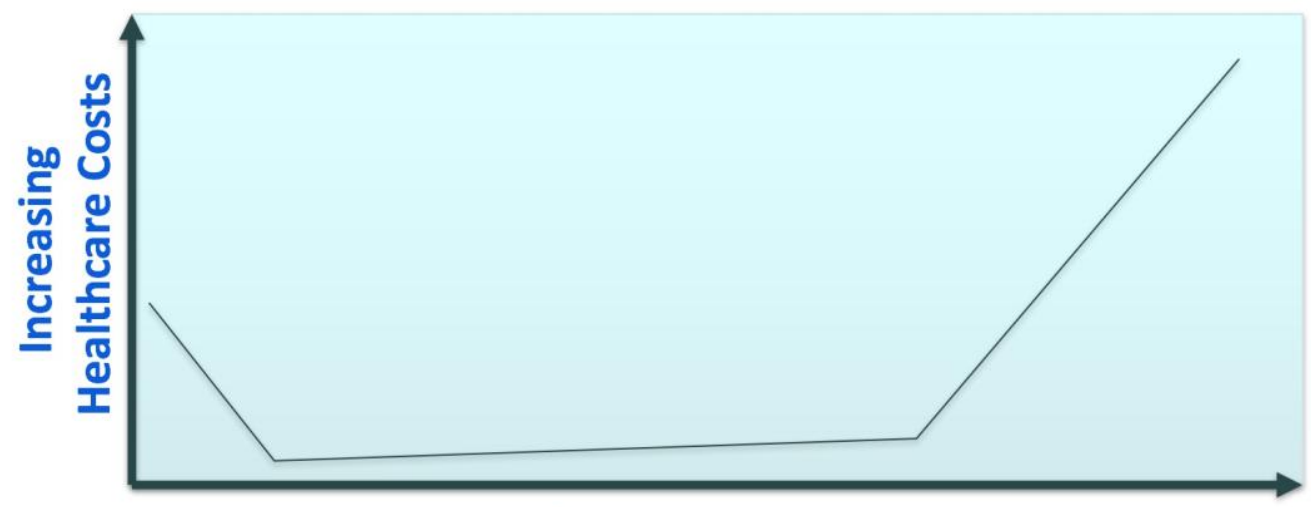

Advancing Age

Figure 1. Relationship between the cost of healthcare with advancing age.

TMT: Where can we go for more information on your insights into telehealth? [04:53]

Dr. Chen: If you are interesting to hear more about this, there is actually a weekly Webinar I'll call "Telehealth Failures and the Secrets to Success."

TMT: Thanks, Dr. Chen for participating in the conference. [05:03]

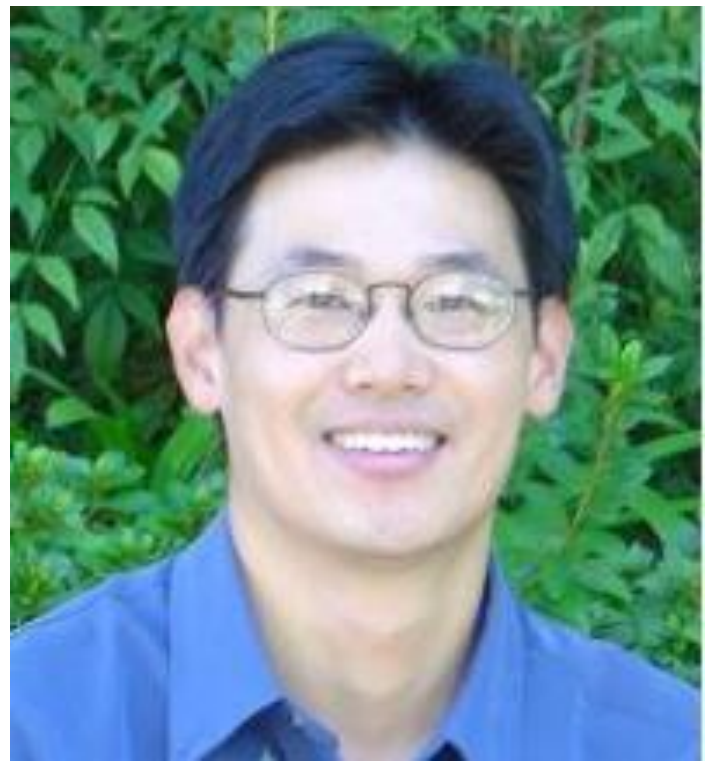


1822. Chen. Interview

https://doi.org/10.30953/tmt.v2.35

Page 5 of 5

Dr. Chen is a co-founder and the CEO of VSee - the only approved video telehealth platform used by NASA astronauts aboard the International Space Station. He completed his PhD at Stanford University where he researched human factors and design of video collaboration. Milton is also the co-author of the XMPP video standard, which is used by Google and Facebook Chat. 